\title{
Reliability of Rapid Diagnostic Tests to Assess Malaria Trends through a Fever Sentinel Surveillance Network in Madagascar, 2013-2015
}

Laurence Randrianasolo ${ }^{1 *}$, Elisabeth Ravaoarisoa ${ }^{2}$, Seheno Razanatsiorimalala ${ }^{2}$, Fanjasoa Rakotomanana ${ }^{1}$, Toky Ramarokoto ${ }^{1}$, Charles Ramarokoto ${ }^{1}$, Léa Randriamampionona ${ }^{1,3}$, Clémence Rakotoarivony ${ }^{3}$, Annett Cotte ${ }^{4}$, Judith Hedje ${ }^{4,5}$, Patrice Piola ${ }^{1,6}$ and Milijaona Randrianarivelojosia ${ }^{2,7}$

${ }^{1}$ Epidemiology and Clinical Research Unit, Institut Pasteur de Madagascar, Madagascar

${ }^{2}$ Malaria Research Unit, Institut Pasteur de Madagascar, Madagascar

${ }^{3}$ Health Watch and Epidemiological Surveillance Department, Ministry of Health Madagascar, Madagascar

${ }^{4}$ Malaria Branch, Division of Parasitic Diseases and Malaria, Center for Global Health, U.S. Centers for Disease Control and Prevention, Atlanta, Georgia, USA

${ }^{5}$ U.S. President's Malaria Initiative, Antananarivo, Madagascar

${ }^{6}$ Institut Pasteur de Cambodge, Phnom Penh, Cambodge

${ }^{7}$ Facultés des Sciences, Université de Toliara, Toliara, Madagascar

*Corresponding author: Laurence Randrianasolo, Epidemiology and Clinical Research Unit, Institut Pasteur de Madagascar, Antananarivo, Madagascar, Tel: (261) 20 22 412 74; E-mail: laurence@pasteur.mg

Received date: July 12, 2018; Accepted date: October 12, 2018; Published date: October 18, 2018

Copyright: (c) 2018 Randrianasolo L, et al. This is an open-access article distributed under the terms of the Creative Commons Attribution License; which permits unrestricted use; distribution; and reproduction in any medium; provided the original author and source are credited.

\begin{abstract}
A fever sentinel surveillance network has been operational since 2007 in the island of Madagascar. In all 34 sentinel sites, all febrile patients are tested with malaria rapid diagnostic tests (RDTs) for pan-LDH and pfHRP2, and data are monitored for diagnostically-confirmed malaria trends. Quality assurances of on-site RDT results are managed by Institut Pasteur de Madagascar (IPM). Special attention is given to storage conditions and compliance with the manufacturer's instructions for RDTs. Results of RDTs stored at facilities are compared with results from microscopy and also with the same RDT batch stored at $25^{\circ} \mathrm{C}$ and below $80 \%$ of humidity at IPM. From January 2013 to December 2015, 33/34 fever sentinel surveillance sites were visited regularly throughout the country. There were neither RDTs storage errors nor expired RDTs in stock at any sentinel sites. 81\% of technicians (61/75) properly used RDTs in accordance with the manufacturer's instructions. The results of 1,635 febrile patients were used for quality assurance. Results of on-site RDTs and those stored at IPM were 99.8\% concordant. Comparison with microscopy resulted in sensitivity of $92.5 \%$, specificity of $97.1 \%$, positive predictive value of $86.0 \%$, and negative predictive value of $98.5 \%(n=1,635)$. These results indicate the reliability of malaria RDT results from the fever sentinel sites. Thus, data collected at fever sentinel sites can be used by the National Malaria Control Program to better understand temporal and spatial trends in malaria transmission across Madagascar.
\end{abstract}

Keywords: Malaria trends; Madagascar; Rapid diagnostic test; Fever sentinel surveillance

\section{Introduction}

A fever sentinel surveillance network has been operational in Madagascar since March 2007. It is a passive and daily surveillance system implemented in 34 health centers. The criterion for declaration is fever (axillary temperature $\geq 37.5^{\circ} \mathrm{C}$ without correction) [1]. Malaria, Dengue Like Syndrome (DLS), Influenza Like Illness (ILI), diarrhoea and fever syndrome are the diseases under surveillance. Following guidelines set forth by the National Malaria Control Program (NMCP), HRP-2/pLDH combination Rapid Diagnostic Tests (RDT) which detects all species of Plasmodium spp are used to confirm malaria. All declared fever cases are tested with an RDT to optimize the use of antimalarial drugs and to encourage the search of a differential diagnosis in the event of a negative RDT result. Several extrinsic and intrinsic factors may influence RDT results. The RDT performance reported by the manufacturer is based on sensitivity, specificity, positive predictive value and negative predictive value; all of which can potentially fluctuate according to field conditions and malaria prevalence [2]. The ability of a fever sentinel surveillance system to reliably detect a malaria outbreak depends on the validity of diagnostic tools as well as the timely capture and transmission of data to public health authorities. Thus, rigorous and regular quality control at the sentinel centers is required to ensure the accuracy and reliability of RDTs used [3]. This study aims to determine the performance of malaria RDTs used to survey fever cases through the fever sentinel surveillance network in Madagascar, from 2013 until 2015.

\section{Method}

\section{Study location}

Madagascar is an island country, where based on the interaction of temperature, rainfall and length of dry season can be divided into four bio-climate zones (i) per-humid on the east coast, (ii) sub-humid on the West coast, (iii) humid in the Central highlands and (iv) semi-arid in the South [4]. The malaria transmission period in Madagascar varies according to the epidemiologic profile, but usually corresponds to the hot, rainy season, which starts in October (year n) and ends in May (year $\mathrm{n}+1)$.

This study was carried out among the health centers participating in fever sentinel surveillance. The network was established in 2007 and is composed of 34 health centers located in 31 health districts (of which four fever sentinel sites are located in Antananarivo) of Madagascar. 
Citation: Randrianasolo L,Ravaoarisoa E, Razanatsiorimalala S, Ramarokoto T, Ramarokoto C, et al. (2018) Reliability of Rapid Diagnostic Tests to Assess Malaria Trends through a Fever Sentinel Surveillance Network in Madagascar, 2013-2015. J Trop Dis 6: 287. doi: 10.4172/2329-891X.1000287

Page 2 of 6

Figure 1 shows the geographical location of all fever sentinel sites across the country.

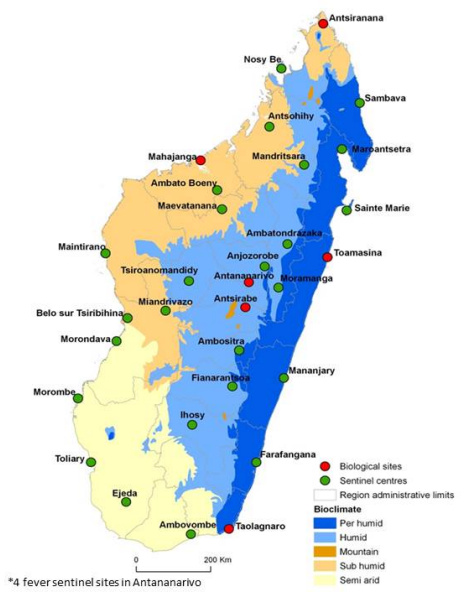

Figure 1: Geographical location of 34 fever sentinel sites, Madagascar 2013-2015.

\section{Questionnaire}

In order to ensure that the manufacturer's procedures and recommendations were applied correctly in the field, malaria RDTs currently used in the sentinel sites were regularly tested for quality assurance. During frequent field supervisions, a technician or physician from Institut Pasteur de Madagascar (IPM) administered a standardized questionnaire to the health care workers that performed RDTs, observed RDT testing procedures (as compared to the manufacturer's instruction), and inspected RDTs on-site storage room temperature and humidity level (reference: $4^{\circ} \mathrm{C}-30^{\circ} \mathrm{C}$ and $<80 \%$ ) [5].

\section{Specimen collection}

The evaluation of RDTs was carried out twice a year: during the rainy season (from October until December and January until June) and during the winter season (from July until September). An IPM technician or physician collected specimens and conducted two malaria RDTs for each fever case declared: one from the sentinel site storage space and the other from IPM's closely monitored storage facility.

Performance of RDTs from the sentinel sites was not only compared to RDTs from IPM storage room, but also to Real Time PCR and microscopy. RDTs sensitivity, specificity, positive predictive value and negative predictive value were measured.

\section{RDT versus RDT}

Each sentinel site was equipped with WHO approved RDTs, which were consistent with the national technical specifications in Madagascar. Two tests, RDTs available in the sentinel site and RDTs stored at IPM, were carried out according to the manufacturer's instructions for each patient. The results were interpreted following the manufacturer's recommendation.

\section{RDT versus microscopy}

Finger-prick blood samples for light microscopy were collected from each included patient during the supervision period. The microscopy examination was performed at IPM in Antananarivo. Giemsa-stained thick blood smears were read by experienced technicians who were blinded to RDT results. Parasite densities were calculated by counting the number of asexual and sexual Plasmodium spp parasites until 1,000 leukocytes were observed and then converting this figure to parasitemia (trophozoits and/or gametocytes) per microliter of blood, assuming an average leukocyte count of $8,000 / \mu \mathrm{L}$. The detection threshold for this method was thus 8 parasites per microliter of blood. Thin blood smears were examined to confirm the identification of the Plasmodium species detected. This examination was carried out at IPM under the supervision and control of a senior scientist. Performance of the RDT available in the sentinel site was then compared to the corresponding microscopy results.

\section{RDT versus PCR}

For each patient included in field investigation, capillary blood was spotted onto a clean filter paper (Whatman $3 \mathrm{MM} \mathrm{Chr}$ ). Each filter paper sample was dried at room temperature and stored in separate plastic packets to avoid cross contamination. Blood samples were transported to IPM and stored at $-20^{\circ} \mathrm{C}$ until processing. PCR analyses were performed at IPM in Antananarivo. The PCR methods allowed detecting the following species of Plasmodium: P. falciparum, $P$. vivax, $P$. malariae and $P$. ovale. DNA was extracted from the blood samples [6]. $P$. falciparum, $P$. vivax and $P$. malariae carriers were detected by Real-Time PCR, as described by de Monbrison and others, with ABI thermocycler (Applied Biosystem, California, USA). Plasmodium ovale detection was performed by using Mangold method $[7,8]$. Performance of the RDT available in the sentinel site was measured within PCR as reference.

\section{Statistical analysis}

Data were recorded with Excel and analysed by R software version 2.7.0 [9]. Sensitivity, specificity, positive predictive value (PPV) and negative predictive value (NPV) were calculated using two-by-two tables. The sensitivity was calculated as the ratio of true positives to the sum of true positives and false negatives, and the specificity as the ratio of true negatives to the sum of true negatives and false positives. The PPV was estimated as the number of true positives divided by the number of RDT positives; and the NPV as the number of true negatives over the number of RDT negatives.

Chi-square test was used to test the difference between age group, year, duration of fever, bio-climate, season and parasitemia. A $\mathrm{p}$ value $\leq 0.05$ was considered as a statistically significant difference.

\section{Ethical considerations}

Data were collected within the activities of the national public health surveillance systems. Specimens were collected as part of the routine care. Physicians explained the purpose of the surveillance system before taking each specimen. Patients were then free to refuse to participate. The specimens used in this study were anonymously identified. The National Ethics Committee considered this study to be a non-interventional activity. 
Citation: Randrianasolo L,Ravaoarisoa E, Razanatsiorimalala S, Ramarokoto T, Ramarokoto C, et al. (2018) Reliability of Rapid Diagnostic Tests to Assess Malaria Trends through a Fever Sentinel Surveillance Network in Madagascar, 2013-2015. J Trop Dis 6: 287. doi: 10.4172/2329-891X.1000287

Page 3 of 6

\section{Result}

\section{RDT storage in site}

Thirty three of the 34 fever sentinel sites were visited from January 2013 until December 2015. RDTs used by the sentinel sites were manufactured by CareStart and $S D$ Bioline which detected all species of Plasmodium spp and identified P. falciparum with the other species [5]. During field investigation, one site experienced a stock out of RDTs (Location: Maintirano); all RDTs available in the sentinel site were stored at $25^{\circ} \mathrm{C}$ and under $80 \%$ of humidity. Thus, there were no RDT storage errors and no expired RDTs in stock in any of the sites visited.

\section{Compliance to manufacturer's instruction on RDT used}

During the field investigation and supervision by IPM teams, 75 technicians (47 nurses, 24 physicians and 4 Community Health Workers) were supervised. Usage procedures of RDTs were in accordance with the manufacturer recommendation (used of examination gloves, open the test packet just before using, put down test cassette on horizontal plane, collected good sized of blood, held the bottle of buffer vertically, added exactly the correct number of buffer, respected duration of the test) in $81.3 \%$ (61/75) of healthcare providers. Manufacturer's recommendations were not fully respected in $25 \%$ of the Community Health Workers (CHW), $19 \%$ of nurses and $16 \%$ of physicians. $75 \%(56 / 75)$ of the technicians had completed their training greater than or equal to two years. Non-compliance regarding time between sampling and reading of the RDT (insufficient in 47\%), assay buffer solution quantity (insufficient or excess in 32\%) and blood sample quantity (less or excess in $21 \%$ ) were the main errors observed. These errors were irrespective of the technician status. All errors were corrected on-site by training and providing additional materials such as gloves and timers.

\section{Data description}

Three on-site RDT results were invalid. A total of 1, 635 patients from 33 sentinel sites were included in the analysis (490 in 2013, 675 in 2014 and 470 in 2015). The sex ratio Male/Female was $0.88(765 / 870)$. The median age was 7.0 years [IQR: 2; 20 years] and $64.8 \%$ $(1060 / 1635)$ were below 15 years. The mean axillary temperature was $38.2^{\circ} \mathrm{C}$ [95\% CI: $38.13 ; 38.21^{\circ} \mathrm{C}$ ] and $90.3 \%(1477 / 1635)$ of patients had a fever (uncorrected axillary temperature $\geq 37.5^{\circ} \mathrm{C}$ ). Seven percent of patient's registries $(112 / 1,635)$ were missing data on fever duration while $93.0 \%$ (1417/1523) of patients attended the sentinel sites within 7 days of fever inception. 1074 RDTs were performed during the rainy season and 561 during the winter season (Table 1).

\section{Case results and RDT positivity rate}

Among the 1,635 included patients, 286 (17.5\%) were confirmed as malaria. Eight patients from Maintirano had not performed on-site RDT (Site-RDT) and therefore the Site-RDT versus IPM-RDT comparison was not possible. All IPM-RDTs were matched with thick blood for microscopy examination of which $16.3 \%$ (266/1635) were positive, mainly with Plasmodium falciparum (97.8\%), Plasmodium vivax $(1.1 \%)$ and mixed infections (1.1\%). Among the positive blood smears, $1.9 \%(5 / 266)$ presented only gametocytes. Twelve $(0.7 \%)$ specimens were not analyzed by RT-PCR and $18.9 \%$ (307/1623) were RT-PCR positive: $95.8 \%$ P. falciparum, $2.3 \%$ P. vivax, $0.3 \%$ P. malariae and $1.6 \%$ mixed infections ( $P$. falciparum and $P$. vivax) $P$. ovale was not detected during this study.

\begin{tabular}{|c|c|c|c|c|c|}
\hline & & $\begin{array}{l}\text { Positivity } \\
\text { rate }(\%)\end{array}$ & $\begin{array}{l}\text { RDTs } \\
\text { Positive }\end{array}$ & $\begin{array}{l}\text { RDTs } \\
\text { tested }\end{array}$ & $p$ \\
\hline \multirow[t]{3}{*}{ Year } & 2013 & 21.0 & 103 & 490 & 0.03 \\
\hline & 2014 & 16.7 & 113 & 675 & \\
\hline & 2015 & 14.9 & 70 & 470 & \\
\hline \multirow[t]{4}{*}{ Bioclimate } & Perhumid & 20.7 & 111 & 537 & $\begin{array}{l}2.009 \\
10-9\end{array}$ \\
\hline & Humid & 8.1 & 35 & 430 & \\
\hline & Subhumid & 23.5 & 115 & 490 & \\
\hline & Semi-aride & 14.0 & 25 & 178 & \\
\hline \multirow[t]{2}{*}{ Season } & $\begin{array}{l}\text { Rainy } \\
\text { season }\end{array}$ & 18.9 & 203 & 1074 & 0.04 \\
\hline & $\begin{array}{l}\text { Winter } \\
\text { season }\end{array}$ & 14.8 & 83 & 561 & \\
\hline \multirow[t]{2}{*}{ Age group } & $<15$ years & 17.1 & 181 & 1060 & 0.59 \\
\hline & $\geq 15$ years & 18.3 & 105 & 575 & \\
\hline \multirow{3}{*}{$\begin{array}{l}\text { Duration of } \\
\text { fever }\end{array}$} & $\leq 7$ days & 14.4 & 110 & 765 & 0.0005 \\
\hline & $>7$ days & 21.2 & 161 & 758 & \\
\hline & $\begin{array}{l}\text { not available } \\
=112\end{array}$ & & & & \\
\hline Total & & 17.5 & 286 & 1635 & \\
\hline
\end{tabular}

Table 1: Variation of RDTs positivity rate $(n=1,635)$, Madagascar, 2013-2015.

RDT positivity rate was analysed by year of study, bio-climate, season, age group, duration of fever and parasitemia. RDT positivity rates decreased over time, from $21.0 \%(103 / 490)$ in 2013, $16.7 \%$ $(113 / 675)$ in 2014 to $14.9 \%(70 / 470)$ in 2015 ; with a statistically significant trend $(\mathrm{p}=0.03)$. By bio-climate, RDT positivity rates were $23.5 \%(115 / 490)$ in sub-humid (western coast), 20.7\% (111/537) in per-humid (eastern coast), $14.0 \%(25 / 178)$ in semi-arid (the south) and $8.1 \%(35 / 430)$ in humid (the central highland); with a statistically significant difference $(\mathrm{p}<0.001)$. RDT positivity rates were $18.9 \%$ (203/1074) during the rainy season and $14.8 \%$ (83/561) during the winter season $(\mathrm{p}=0.04)$. When we looked at age groups $\geq 15$ years and $<15$ years, RDT positivity rates were respectively $18.3 \%(105 / 575)$ and $17.1 \%$ (181/1060), without any statistically significant difference $(\mathrm{p}=0.59)$. There was a $14.4 \%(110 / 765)$ RDT positivity rate among individuals consulting within 7 days after the fever started and $21.2 \%$ $(161 / 758)$ when consulting after seven days $(\mathrm{p}<0.001)$. With regards to parasitemia, RDTs positivity rate was $5.6 \%(72 / 1289)$ at $<1000 / \mu \mathrm{l}$ and $13.4 \%(189 / 1406)$ at $\geq 1000 / \mu \mathrm{l},(\mathrm{p}<0.001)$ (Table 2$)$.

\begin{tabular}{|l|l|l|}
\hline Variables & n & (\%) \\
\hline On-site RDTs results & 281 & 17.2 \\
\hline Positive & 1346 & 82.3 \\
\hline Negative & 1346 \\
\hline
\end{tabular}


Citation: Randrianasolo L,Ravaoarisoa E, Razanatsiorimalala S, Ramarokoto T, Ramarokoto C, et al. (2018) Reliability of Rapid Diagnostic Tests to Assess Malaria Trends through a Fever Sentinel Surveillance Network in Madagascar, 2013-2015. J Trop Dis 6: 287. doi: 10.4172/2329-891X.1000287

Page 4 of 6

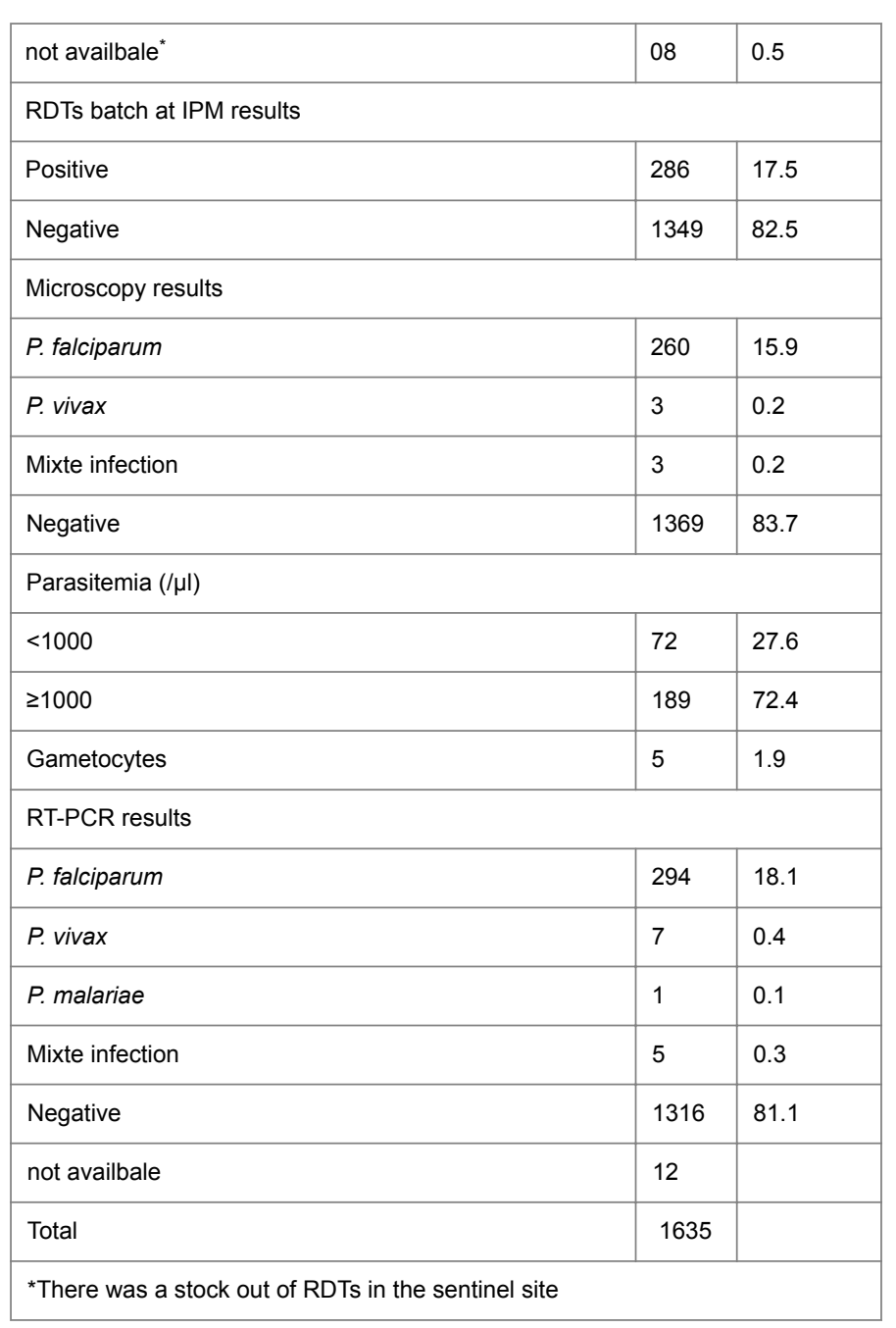

\section{RDT performance analysis}

RDTs were performed and the results were interpreted according to the manufacturer's recommendation. Three invalid tests $(0.18 \%)$ were recorded. The results of 1,635 febrile patients out of 1,638 were used for quality assurance. Results of on-site RDTs and those stored at IPM were $99.8 \%$ concordant.

Compared with microscopy as gold standard $14.0 \%$ (40/286) positive by RDTs were negative and $1.5 \%$ (20/1349) negative by RDTs were positive. Sensitivity, specificity, PPV and NPV of RDTs were respectively 92.5\% [95\% CI: 92.35-92.65], 97.1\% [95\% CI: 97.03-97.17], 86.0\% [95\% CI: 85.76-86.24] and 98.5\% [95\% CI: 98.47-98.53]. RDT sensitivity varied by bioclimate $93.9 \%$ in perhumid, $93.5 \%$ in subhumid, $88.6 \%$ in humid and $87.5 \%$ in semi-aride $(\mathrm{p}=0.002)$.

In order to understand the variation of RDTs sensitivity, parasitemia was categorized into two groups: $<1,000 / \mu \mathrm{l}$ and that $\geq 1,000 / \mu \mathrm{l}$. Considered the parasitemia was less than $1000 / \mu$; sensitivity, specificity, PPV and NPV of RDTs were $92.8 \%, 99.4 \%, 88.9 \%$ and $99.6 \%$ respectively. These results compared with parasitemia greater than or equal of $1,000 / \mu l$, were no statistically significant.

Compared with RT-PCR as reference, 5.6\% (16/286) positive by RDTs were negative and 2.8\% (37/1300) negative by RDT_IPM were positive. Sensitivity, specificity, PPV and NPV were $87.9 \%$ [95\% CI:

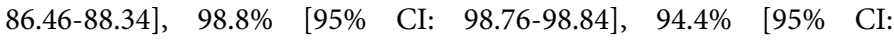
94.27-94.53] and 97.2\% [95\% CI: 97.12-97.25] respectively. Sensitivity was very low during winter season than rainy season $(\mathrm{p}=0.001)$. With parasitemia less than 1000/ $\mu$ l; sensitivity and PPV of RDTs were $56.3 \%$ and $93.1 \%$ respectively. These results compared with parasitemia greater than or equal of $1,000 / \mu l$, had significant difference $(\mathrm{p}=2.574$, 10-5 and 0.008). The highest sensitivities were recorded at parasitemia $\geq 1,000 / \mu \mathrm{l}$ and the performance dropped if parasitemia $<1,000 / \mu \mathrm{l}$ (Table 3)

Table 2: Number of malaria confirmed for each exam method to study RDTs performance ( $n=1635)$, Madagascar, 2013-2015.

\begin{tabular}{|c|c|c|c|c|c|c|c|c|c|}
\hline & & Sensitivity (\%) & $\mathbf{p}$ & PPV (\%) & $\mathbf{p}$ & Specificity (\%) & $\mathbf{p}$ & NPV (\%) & $\mathbf{p}$ \\
\hline \multicolumn{10}{|l|}{ By microscopy } \\
\hline Year & $\begin{array}{l}2013 \text { vs } 2014 \text { vs } \\
2015\end{array}$ & $\begin{array}{l}87.0 \text { vs } 95.2 \text { vs } \\
95.7\end{array}$ & 0.04 & $\begin{array}{l}77.7 \text { vs } 88.5 \text { vs } \\
94.3\end{array}$ & 0.005 & $\begin{array}{l}94.2 \text { vs } 97.7 \text { vs } \\
99.0\end{array}$ & 0.0001 & $\begin{array}{l}96.9 \text { vs } 99.1 \text { vs } \\
99.3\end{array}$ & 0.007 \\
\hline Bioclimate & $\begin{array}{l}\text { Perhumid vs } \\
\text { subhumid vs humid } \\
\text { vs semi-aride }\end{array}$ & $\begin{array}{l}93.9 \text { vs } 93.5 \text { vs } \\
88.6 \text { vs } 87.5\end{array}$ & 0.002 & $\begin{array}{l}83.8 \text { vs } 87.8 \text { vs } \\
88.6 \text { vs } 84.0\end{array}$ & ns & $\begin{array}{l}95.9 \text { vs } 96.3 \text { vs } \\
99.0 \text { vs } 97.4\end{array}$ & 0.04 & $\begin{array}{l}98.6 \text { vs } 98.1 \text { vs } \\
99.0 \text { vs } 98.0\end{array}$ & ns \\
\hline Season & Rainy vs Winter & 94.1 vs 88.6 & ns & 86.7 vs 84.3 & ns & 97.0 vs 97.3 & ns & 98.7 vs 98.1 & ns \\
\hline Age group & $\begin{array}{l}<15 \text { years vs } \geq 15 \\
\text { years }\end{array}$ & 93.0 vs 91.5 & ns & 88.4 vs 81.9 & ns & 97.6 vs 96.0 & ns & 98.6 vs 98.3 & ns \\
\hline Duration of fever & $\leq 7$ days vs $>7$ days & 92.0 vs 92.9 & ns & 83.6 vs 88.8 & ns & 97.3 vs 97.0 & ns & 98.8 vs 98.2 & ns \\
\hline \multirow{3}{*}{$\begin{array}{l}\text { Parasitemia } \\
\text { body }\end{array}$} & $<1000 / \mu \mathrm{l} v s \geq 1000 / \mu \mathrm{l}$ & 92.8 vs 97.3 & ns & 88.9 vs 94.7 & ns & 99.4 vs 99.3 & & 99.6 vs 99.6 & \\
\hline & RDT performance & 92.5 & & 86,0 & & 97.1 & & 98.5 & \\
\hline & $(95 \% \mathrm{Cl})$ & $(92.35-92.65)$ & & $(85.76-86.24)$ & & (97.03-97.17) & & (98.47-98.53) & \\
\hline
\end{tabular}


Citation: Randrianasolo L,Ravaoarisoa E, Razanatsiorimalala S, Ramarokoto T, Ramarokoto C, et al. (2018) Reliability of Rapid Diagnostic Tests to Assess Malaria Trends through a Fever Sentinel Surveillance Network in Madagascar, 2013-2015. J Trop Dis 6: 287. doi: 10.4172/2329-891X.1000287

Page 5 of 6

\begin{tabular}{|c|c|c|c|c|c|c|c|c|c|}
\hline \multicolumn{10}{|l|}{ By RT-PCR } \\
\hline Year & 2013 vs 2014 vs 2015 & $\begin{array}{l}84.7 \text { vs } 90.7 \text { vs } \\
88.5\end{array}$ & 0.0001 & $\begin{array}{l}91.3 \text { vs } 94.7 \text { vs } \\
98.6\end{array}$ & ns & $\begin{array}{l}97.5 \text { vs } 98.9 \text { vs } \\
99.7\end{array}$ & 0.02 & $\begin{array}{l}95.5 \text { vs } 98.0 \text { vs } \\
97.8\end{array}$ & 0.02 \\
\hline Bioclimate & $\begin{array}{l}\text { Perhumide vs } \\
\text { subhumide vs humide } \\
\text { vs semi-aride }\end{array}$ & $\begin{array}{l}88.6 \text { vs } 88.2 \text { vs } \\
85.0 \text { vs } 88.5\end{array}$ & ns & $\begin{array}{l}91.0 \text { vs } 97.4 \text { vs } \\
97.1 \text { vs } 92.0\end{array}$ & ns & $\begin{array}{l}97.6 \text { vs } 99.2 \text { vs } \\
99.7 \text { vs } 98.7\end{array}$ & 0.04 & $\begin{array}{l}96.9 \text { vs } 96.0 \text { vs } \\
98.5 \text { vs } 98.0\end{array}$ & ns \\
\hline Season & Rainy vs Winter & 92.2 vs 79.2 & 0.001 & 93.6 vs 96.4 & ns & 98.5 vs 99.3 & ns & 98.1 vs 95.6 & 0.01 \\
\hline Age group & $\begin{array}{l}<15 \text { years vs } \geq 15 \\
\text { years }\end{array}$ & 92.0 vs 83.8 & ns & 95.0 vs 93.3 & ns & 99.0 vs 98.5 & 0.01 & 98.3 vs 95.9 & 0.01 \\
\hline Duration of fever & $\leq 7$ days $v s>7$ days & 86.7 vs 88.4 & ns & 94.5 vs 95.0 & ns & 99.1 vs 98.6 & ns & 97.5 vs 96.6 & ns \\
\hline \multirow{3}{*}{ Parasitemia } & $<1000 / \mu \mathrm{l} \mathrm{vs} \geq 1000 / \mu \mathrm{l}$ & 56.3 vs 78.3 & $2.510-5$ & 93.1 vs 99.5 & 0.008 & 99.6 vs 99.9 & & 96.2 vs 96.2 & \\
\hline & RDT performance & 87.9 & & 94.4 & & 98.8 & & 97.2 & \\
\hline & $(95 \% \mathrm{Cl})$ & $(86.46$ - 88.34) & & $(4.27-94.53)$ & & $(98.76$ - 98.84) & & $(97.15-97.25)$ & \\
\hline
\end{tabular}

Table 3: Validity and reliability of RDTs compared by microscopy and RT-PCR, n=1,635, Madagascar, 2013-2015.

\section{Malaria trends through fever sentinel sites}

In each fever sentinel site, data on confirmed malaria cases is aggregated and submitted daily through Short Message Services (SMS). From January 2009 until December 2016, fever cases represented $12.6 \%$ of 2117518 outpatient visits (all age and gender). The overall proportion of RDTs used was $96.8 \%(257246 / 265697)$ of which $17.3 \%$ (44519/257246) were RDTs positive (Figure 2). The proportions of sites that respected timeliness and completeness were respectively $47.4 \%$ [95\% CI: 43.8; 50.9] and $90.8 \%$ [95\% CI: 89.2; 92.4]. This surveillance system used a web-based malaria early warning system and performed to identify the malaria upsurge, an example was published by Kesteman et al. [10].

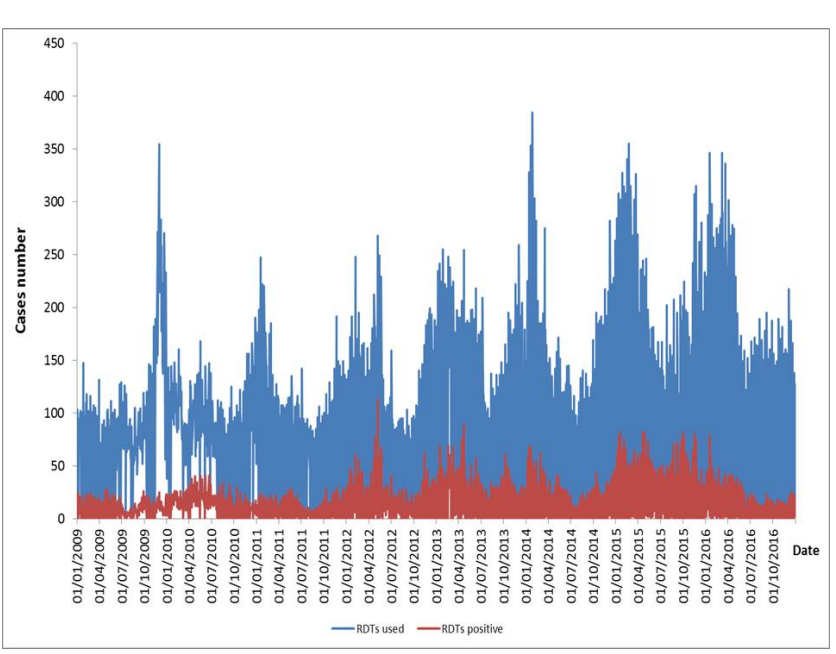

Figure 2: Malaria trends through fever sentinel surveillance network, Madagascar, 2006-2016.

\section{Discussion}

Results show that the sensitivity and PPV of RDTs decreased with parasitemia. RDT performance was not influenced by age, duration of fever and axillary temperature. Regular supervision was crucial to maintain good quality data collection at sentinel sites in Madagascar.

Malaria RDTs available in the sentinel sites detected all species of Plasmodium spp. During the field investigation, there were no RDTs storage errors and no expired RDTs in stock. One sentinel site experienced stock out of RDTs. During supervision, $81.3 \%(61 / 75)$ of technicians adequately used the RDTs in accordance with the manufacturer's recommendations; suggesting that ongoing regular supervisions are necessary to maintain quality assurance of RDTs used at fever sentinel sites. Supervision would ensure that all procedures and recommendations are consistently followed. Refresher trainings on RDT use were provided to all health center workers and additional timers were provided. Results of on-site RDTs and those stored at IPM were $99.8 \%$ concordant. It might be interpreted that there was no error of RDTs transportation from the national storage facility to peripheral sentinel sites [11].

Malaria is a deadly disease that needs accurate diagnosis and treatment. The use of RDTs at the primary health centers and especially in the remote rural areas has rapidly increased over the past few years [12]. These results show that RDTs were reliable to diagnose malaria. WHO Malaria RDTs Product Testing published annually since 2009 forms the basis of procurement criteria of RDTs. The RDTs evaluation led by WHO tests RDTs against a panel of parasite samples diluted to a low parasite density (200 parasites/ $\mu \mathrm{l})$ and a higher parasite density (2000-5000 parasites/ $\mu$ l). The WHO evaluation doesn't include a measure of RDT performance in clinical settings. This study aimed to evaluate the performance of RDTs in different epidemiological profile in Madagascar and in different time periods by comparing them with microscopy and RT-PCR results. Regardless of the malaria endemicity, specificity and NPV were $94 \%$ and above $[13,14]$. These results suggested that Artemisinin Combination Therapy (ACTs) was only provided for malaria case management and not for other illnesses. The use of ACTs was optimized. 
Citation: Randrianasolo L,Ravaoarisoa E, Razanatsiorimalala S, Ramarokoto T, Ramarokoto C, et al. (2018) Reliability of Rapid Diagnostic Tests to Assess Malaria Trends through a Fever Sentinel Surveillance Network in Madagascar, 2013-2015. J Trop Dis 6: 287. doi: 10.4172/2329-891X.1000287

Page 6 of 6

RDTs positivity rate was higher during rainy season than winter season and increased in the different bioclimate in parallel of the transmission intensity. Clearly, it can be argued that the variability observed between the two seasons (malaria transmissions) and in the four bioclimate resulted from performance variability of the $\mathrm{pLDH}$ based malaria RDTs $[15,16]$. Thus RDTs performance in the various malaria epidemiological profiles should be reviewed periodically to ensure the malaria case management in Madagascar.

The elimination of malaria in Madagascar requires an effective epidemiological surveillance system; the data quality collected by the routine surveillance was often limited in terms of completeness and timeliness [17]. Fever sentinel surveillance network has filled the gap in producing timely data analysis with high quality data, something the routine surveillance system has been struggling with. In addition the sentinel surveillance network has provided the opportunity to monitor more accurately malaria trends in Madagascar by using epidemic prone disease differential diagnostic and identify malaria outbreaks with enough lead time that response efforts could be implemented.

\section{Conclusion}

In Madagascar, the lack of integrated information systems and the limited number of qualified microscopists available are strong arguments to use RDTs to monitor the burden of malaria and its trends over time. Thus, rigorous and regular quality control at health centers is required to ensure the accuracy and reliability of RDTs used. Moreover, Madagascar plans to move towards malaria elimination, prompt malaria case diagnosis and treatment needs to continue to be strengthened and more sensitive diagnostics tools may need to be explored especially for the pre-elimination areas where parasite densities are lower.

\section{Acknowledgment}

We are grateful to all those who participated in this study, including, in particular, Arthur Randrianantenaina, Andritsilavo Jean Narivelo and Lucie Randrianarivony from Epidemiology and clinical research Unit, Rogelin Raherinjafy, Martial Jahevitra, Tianasoa Andriamiandranoro and Elie Noro Raholimalala from Malaria Research Unit of the Institut Pasteur de Madagascar, for their technical and administrative assistance. We are also thanking all head of the fever sentinel sites from the Ministry of Public Health for their cooperation during the field investigation.

\section{References}

1. Randrianasolo L, Raoelina Y, Ratsitorahina M, Ravololomanana L, Andriamandimby S, et al. (2010) Sentinel surveillance system for early outbreak detection in Madagascar. BMC Public Health 10:1471-2458.

2. World Health Organisation, WHO (2003) Malaria rapid diagnosis, making it work. Meeting report.

3. World Health Organisation, WHO (2008) Methods manual for laboratory quality control testing of malaria rapid diagnostic tests.

4. Initiative roll back malaria, Groupe de Recherche sur le Paludisme, Institut Pasteur de Madagascar : Atlas évolutif du paludisme à Madagascar. (2002) Edited by Institut Pasteur de Madagascar, Antananarivo.

5. Randrianarivelojosia M, Raherinjafy RH, Migliani R, Mercereau-Puijalon $\mathrm{O}$, Ariey F, et al. (2004) Plasmodium falciparum resistant to chloroquine and to pyrimethamine in Comoros Parasite 11:419-423.
6. Mangold KA, Manson RU, Koay ES, Stephens L, Regner M, et al. (2005) Real-time PCR for detection and identification of Plasmodium spp. J Clin Microbiol 43:2435-2440.

7. de Monbrison F, Angei C, Staal A, Kaiser K, Picot S (2003) Simultaneous identification of the four human Plasmodium species and quantification of Plasmodium DNA load in human blood by real-time polymerase chain reaction. Trans R Soc Trop Med Hyg 97:387-90.

8. R version 3.0.0 (2013) Masked Marvel. Copyright (c) 2013 The R Foundation for Statistical Computing.

9. Kesteman T, Randrianarivelojosia M, Mattern C, Raboanary E, Pourette D, et al. (2014) Nationwide evaluation of malaria infections, morbidity, mortality, and coverage of malaria control interventions in Madagascar. Malaria Journal 13:465.

10. World Health Organisation, WHO (2011) Global Malaria Programme. Universal access to malaria diagnostic testing. An operational manual.

11. Ministry of health, family planning and social protection (2007) strategic plan for the fight against malaria. From control to malaria elimination in Madagascar. 2007-2012, Antananarivo, Madagascar.

12. World Health Organisation, WHO (2012) Malaria rapid diagnostic test performance, Results of WHO product testing of malaria RDTs.

13. Smith T, Killeen G, Lengeler C, Tanner M (2004) Relationships between the outcome of Plasmodium falciparum infection and the intensity of transmission in Africa. Am J Trop Med Hyg 71: 80-86.

14. Amidou Diarra A, Nébié I, Tiono A, Sanon S, Soulama I, et al. (2012) Seasonal performance of a malaria rapid diagnosis test at community health clinics in a malaria-hyperendemic region of Burkina Faso. Parasites and Vectors 5:103.

15. Hopkins H, Bebell L, Kambale W, Dokomajilar C, Rosenthal PJ, et al. (2008) Rapid diagnostic tests for malaria at sites of varying transmission intensity in Uganda. J Infect Dis 197: 510-518.

16. Chilundo B, Sundby J, Aanestad M (2004) Analysing the quality of routine malaria data in Mozambique. Malar J 3:3.

17. Butts J, Menon M, Yoon S (2010) Health facility surveillance: An assessment of data quality and Use. Amercian Society of Tropical Medicine and Hygiene, 59th Annual Meeting-Atlanta. 